publication take on journalistic responsibilities along with the science.

Hidde Ploegh is in the Department of Pathology,

Harvard Medical School, 200 Longwood Avenue,

Boston, Massachusetts 02115, USA.

www.embo-reports.oupjournals.org

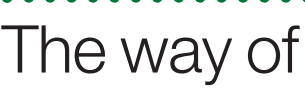

\section{the future?}

BioMed Central (online only)

editorial directors Peter Newmark (biology)

\& Fiona Godlee (medicine)

BioMed Central. Access free

\section{William Hersh}

There is a growing concern among scientists that research results are controlled by an increasingly small number of publishers who have great control over the marketplace. This monopoly, however, is indirectly supported by scientists themselves, who aim to publish in the most prestigious and wellcited journals and need those publications to obtain promotion and grant funding. A related concern is that governments fund most basic research, individual scientists perform it, and then reports of the results are handed over to publishers who assume the copyright and sell it back to those very governments and scientists. Because many scientific journals are costly, accessing them is increasingly beyond the reach of both individuals and libraries, the latter of whom are increasingly strapped financially.

These concerns have been addressed by a number of individuals and organizations. In 1999, the US National Institutes of Health (NIH) announced an initiative, E-Biomed, later renamed PubMed Central (PMC), which would provide a repository of scientific research papers that could be accessed free over the World Wide Web. The proposal met with much controversy, especially the part, later dropped, that proposed an additional repository of papers before peer review.

After considerable debate - and some retrenching on the part of NIH - PMC has gone live and currently has about a dozen journals available (www.pubmedcentral. gov). One restriction whose relaxation has led to more journals joining the PMC initiative has been the abandonment of the requirement for articles to be physically located on the PMC site. Now journal publishers need only provide links to PMC and keep their papers on their own sites. Some view the PMC model as an extension of the approach used by GenBank, where data from genomics research are made widely accessible.

Another initiative to make research articles more widely and freely available is the
Public Library of Science (PLS; www.publiclibraryofscience.org): scientists who sign the PLS open letter pledge only to publish in and subscribe to those journals that agree to make their research reports freely available within six months of publication on the web via $\mathrm{PMC}$ or any other equivalent model. More than 28,000 scientists in 172 countries have currently signed the letter, agreeing to adhere to the pledge from this September. These initiatives have been debated vigorously in many forums, including the Nature website (www.nature.com/nature/ debates/e-access/index.html).

A new approach to scientific publishing that is completely electronic and incorporates the goals of PMC and PLS has now been launched by BioMed Central (BMC). This is an initiative based in the United Kingdom to provide "peer reviewed research across all areas of biology and medicine, with immediate, barrier-free access for all". Of course, such a goal requires a business model, and BMC is currently supported through advertising on its site. It plans, in the future, to charge authors for processing and editing of their papers,

although this charge will be waived for those unable to afford it. Ultimately, the BMC model views the costs of publishing, which are greatly reduced in the electronic model, as a cost of research to be borne by those who fund it, such as government agencies and commercial concerns.

BMC currently houses 18 biology and 39 medicine journals, each named and devoted to specific subject areas, for example, $B M C$ Bioinformatics and BMC Physiology. The site also contains four affiliated journals as well as abstracts from a small number of scientific meetings. Articles are published in native HTML web-page format as well as a more visually pleasing and better-printing PDF format. A relatively simple search engine allows searching of individual journals or all titles across the site. The search engine also allows queries to be passed to PubMed or PMC. All publications in BMC, since its inception, have been part of PMC and meet the criteria of the PLS.

The BMC publishing process has many aspects that will appeal to scientists. First, the peer-review process is rapid - the website claims that the time from submission to publication averages 35 days. This is due to the use of a completely electronic process, including online submission and peer review. In addition, because all publishing is electronic, articles can be published as soon as they are accepted.

The BMC website also boasts other advantages to its process, including the lack of space constraints, which means that papers worthy of publication do not need to compete with one another for finite space as in print journals. Authors also maintain copyright of their articles, although they grant BMC an exclusive licence to republish the article, even in print form. As all BMC articles are indexed in Medline, research published in BMC is no more difficult to find than that published elsewhere. BMC also provides a standard means for citing articles, which should ensure that they are easy to cite as well as access. Finally, the organization is working with a number of large-scale archiving efforts, such as the Open Archives Initiative (www. openarchives.org), to ensure that content is accessible in perpetuity.

There is concern, of course, that articles published in BMC may not have the 'prestige' associated with traditional scientific publishing. Certainly, there is no inherent reason why high-quality science cannot be published under this model. To assess the quality of science in BMC, I suggest that each reader assess the BMC website articles from his or her field. I can say that articles from my own field (medical informatics) are all of good quality, even though the most cutting-edge research is still pub-

lished in the traditional print journals. But this will change if more top-notch research is submitted to BMC and efforts like it. I have served as a peer reviewer for BMC and can state that I applied my usual rigour to the process.

I believe that BMC represents the future of scientific publishing, and that such a future has great potential. In this era of electronic publishing and growing concern over access to research papers, the BMC model represents a credible alternative. Its success and that of similar efforts depend upon we scientists and our decisions to submit articles to BMC and to cite those it has published. To its credit, BMC does not shrink from the notion that there are costs to scientific publishing, even though they can be reduced by using electronic processes. For BMC and similar models to succeed, those who fund research must realize that the modest cost of publication is a reasonable one that should be associated with research.

William Hersh is in the Division of Medical Informatics \& Outcomes Research, School of Medicine, Oregon Health \& Science University, 3181 SW Sam Jackson Park Road, BICC, Portland, Oregon 97201, USA.

www.biomedcentral.com 